\title{
Improving the link between fisheries science and management: biological, social and economic considerations
}

The fisheries world is special in that it has undergone, within two generations, an institutional, technical, economic and legal upheaval far beyond anything found in most renewable natural resource sectors. Of course, forestry, the energy sector and water have also seen change but rarely have so many natural or anthropological factors combined so as to re-model the interface between Nature, Science and Society.

The statutory scientific meeting of the International Council for the Exploration of the Sea was held in St John's, Canada in September 1994. As usual, scientists from all parts of the world met to try to advance knowledge and methods, to exchange data, to improve the relations between different disciplines and to report on work undertaken in the various committees and working groups.

On the agenda of the Conference, one session title was sufficiently unusual that delegates paid particular attention to it: "Improving the link between fisheries science and management: biological, social and economic considerations". Through this session, we were asked to begin discussion within ICES at the interface between natural and social sciences. This was an important step in an on-going enlargement process. It is this that the journal "Aquatic Living Resources" has recognised in publishing this special issue comprising articles illustrating some of the points that were discussed in the process of building links between the Natural and Social Sciences. These articles have been chosen from among the sixty or so which were presented during the three days of debate. On their own they cannot hope to cover all of the suggestions made for closing the gap between the disciplines but they do demonstrate the various methodological approaches as well as the absolute necessity for multi-disciplinary analysis of questions relating to managing the exploitation of living marine resources. This publication aims to underline the success of this first initiative and to develop the debates that were begun.

The following themes were discussed, from which the papers presented here are taken: "North Atlantic overview and Canadian case history", "Property rights", "Objectives, decisionmaking and institutional constraints", "The importance of people in successful fisheries management".

The order of the papers was determined by the desire, at the ouset, to pose the management problem as it is perceived by the social sciences which are, a priori, furthest from any kind of institutional or even informal implication in the methods or systems of management that currently exist. Hence, P. M. Clay with J. R. McGoodwin followed by M. E. Smith discuss the importance of social variables in the control of the dynamics of productive systems. They also consider, through their representation of the systems being studied, the effects of social variables on the way in which decisions are made concerning the management of exploitation. Moving on from this point, different ways of representing and bringing together social and natural variables are considered, noting the efforts which have been made to represent the dynamics of interactions between productive and management systems, and also (and this is the essential point) the positioning of the central questions with respect to the management of these dynamics. P. Lane and R. Stephenson make some propositions towards the definition of a "Science of Fisheries Management" which they want to operationalise to take account not only of the objectives of management but also of performance measurement, risk evaluation, and monitoring of the differences between goals and achievements. J. Catanzano and B. Mesnil draw attention to the development of a representational framework for the dynamics of these systems, themselves components of the fisheries system. In order to do this they develop 
an analytical framework adding in, step by step, some of the major questions posed by the concepts of risk and uncertainty. A. T. Charles discusses in the context of multi-disciplinarity some of the major question of concern to all disciplines concerned with fisheries science. Over and above their individual messages, taken together these tests put the spotlight clearly on the major question of the management of exploitation and at the same time show the importance of understanding human behaviour, of both those involved in the productive system and those involved in the management system.

To support these discussions we have decided to conclude this special issue by looking at a few well-documented fisheries from different contexts. The reader will find papers on European fisheries management by G. Biais; on the snow-crab fisheries of the Gulf of St Lawrence by Loch et al.; on the scallop fisheries of Nova Scotia by L. Brander and D. L. Burke; and on Canadian Atlantic fisheries policy by M. Gardner. Quite apart from the diversity of social, biological and ccological contexts in each of these cases and apart also from the intrinsic interest in the results of the different regulatory systems in each case, the reader should find, in this confrontation of concrete situations and the preceding methodological debate, the inspiration to continue the conceptualisation effort which underlies the exchanges between disciplines. We hope that readers will, through these papers, be brought to reconsider the problems to which their own research relates. That at least is the challenge that we set ourselves.

Joseph Catanzano

Economiste, Dir. de Recherches, ORSTOM, Département TOA, Paris. 